\title{
Application of a C-Type Filter Based LCFL Output Filter to Shunt Active Power Filters
}

\author{
Cong $\mathrm{Liu}^{\dagger}, \mathrm{Ke} \mathrm{Dai}^{*},{ }$ Kewei Duan ${ }^{* *}$, and Yong Kang ${ }^{*}$ \\ ${ }^{* *}$ State Key Laboratory of Advanced Electromagnetic Engineering and Technology, School of Electrical and \\ Electronic Engineering, Huazhong University of Science and Technology, Wuhan, China \\ ${ }^{* *}$ Electric Power Training Center, State Grid Hunan Electric Power Company, Changsha, China
}

\begin{abstract}
This paper proposes and designs a new output filter called an LCFL filter for application to three phase three wire shunt active power filters (SAPF). This LCFL filter is derived from a traditional LCL filter by replacing its capacitor with a C-type filter, and then constructing an L-C-type Filter-L (LCFL) topology. The LCFL filter can provide better switching ripple attenuation capability than traditional passive damped LCL filters. The LC branch series resonant frequency of the LCFL filter is set at the switching frequency, which can bypass most of the switching harmonic current generated by a SAPF converter. As a result, the power losses in the damping resistor of the LCFL filter can be reduced when compared to traditional passive damped LCL filters. The principle and parameter design of the LCFL filter are presented in this paper, as well as a comparison to traditional passive damped LCL filters. Simulation and experimental results are presented to validate the theoretical analyses and effectiveness of the LCFL filter.
\end{abstract}

Key words: Active filters, Grid connection, Harmonics, Power quality, Voltage source converters

\section{INTRODUCTION}

Voltage source converters (VSCs) have been widely used in many application fields, such as distributed generations [1]-[3], microgrids [4], shunt active power filters (SAPFs) [5]-[7], adjustable speed drivers (ASDs) [8], uninterruptible power supplies (UPS) [9], etc. The proper implementation of close-loop current control schemes and pulse-width modulation (PWM) strategies in a VSC can insure good current output performance within its control bandwidth. However, the switching harmonic currents associated with the PWM process of the VSC still need to be attenuated by an output filter, otherwise they may cause harmonic interference and EMI problems in the grid or other facilities [10].

The output filter or grid interface filter of a VSC is essential to its output current quality. Traditionally, an inductor is connected at the ac output terminal of a VSC as an interface

Manuscript received Dec. 21, 2012; revised Jul. 26, 2013 Recommended for publication by Associate Editor Sung-Yeul Park.

${ }^{\dagger}$ Corresponding Author: congcong_liu@foxmail.com

Tel: +86-2787553354, Fax: +86-2787559303, Huazhong University of Science and Technology

* State Key Laboratory of Advanced Electromagnetic Engineering and Technology, School of Electrical and Electronic Engineering, Huazhong University of Science and Technology, China

${ }^{* *}$ Electric Power Training Center, State Grid Hunan Electric Power Company, Changsha, China filter. However, a high inductance is required to obtain good harmonic attenuation performance, which may affect the dynamic characteristic and cause an over-modulation problem [5]. An LCL filter is a better solution than an L filter, because it can attenuate high-frequency harmonic well with a smaller output inductance and a reduced size and cost [5], [11]-[15]. However, a serious challenge faced by the LCL filter is its resonance problem, which may make the whole system unstable and degrade the output performance of the VSC [16], [17]. Fortunately, this LCL filter resonance problem can be solved with different damping methods, which can be classified as passive damping [18]-[20] and active damping [13], [21]-[26].

Active damping methods may require the measurement of some extra electrical variables for resonance damping control purposes, or complicated controllers are needed to alleviate the resonance problem. Some typical implementations of active damping methods are based on sensing the filter capacitor currents, voltages, or both for complete state feedback. Since active damping may increase the overall system costs and implementation complexity [26], passive damping methods seems to be more attractive in some cases.

Passive damping is implemented by adding some passive components to the original LCL filter [18]-[20]. Different passive damping configurations of the LCL filter are shown as 


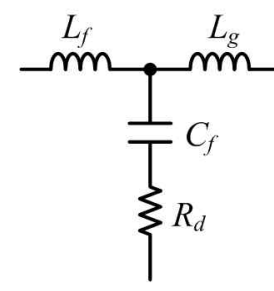

(a)

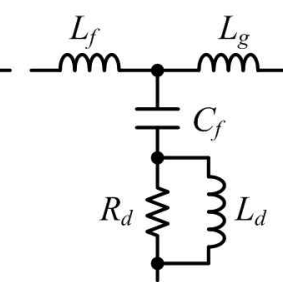

(b)

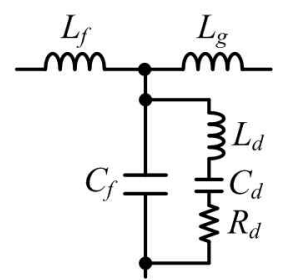

(c)

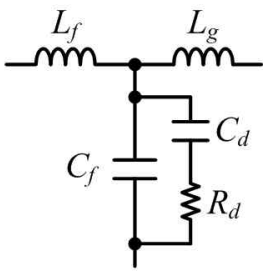

(d)

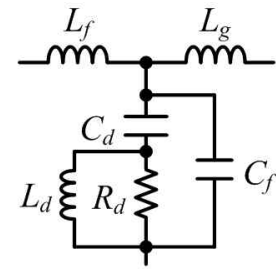

(e)
Fig. 1. Different passive damping configurations of LCL filter.

Fig. 1 [18]. Fig. 1(a) shows the single resistor passive damping method of the LCL filter, in which a damping resistor $R_{d}$ is connected in series with the filter capacitor $C_{f}$. This method is simple and straightforward, but the power losses of the damping resistor may be very high and will decrease the overall system efficiency. Moreover, the switching harmonic attenuation performance of the LCL filter may be degraded by the passive damping. Therefore, it is desirable to find some other passive damping solutions with less power losses for the LCL filter [18], [21], such as those shown as Fig. 1 (b)-(e). These methods are basically focused on reducing low frequency power losses. This is done by reducing the fundamental currents that flow through the damping resistor. Meanwhile, the switching harmonic attenuation performance may be affected.

This paper proposes and designs an new output filter for application to a three phase three wire SAPF. This new output filter is derived from a traditional LCL filter by replacing its capacitor with a C-type filter [27]-[29]. Therefore, it has an L-C-type filter-L (LCFL) structure and has been named an LCFL filter. It must be noted that the C-type filter adopted in the LCFL filter is not the same as that commonly referred to in the literature. Traditionally, C-type filters have been mainly used as independent passive power filters (PPFs) in industrial applications fields, such as iron and steel plants [27], HVDC projects [28], [29], and so on. There are also papers that discuss the applications of a C-type filter together with an APF [30]-[33]. However, in those papers, the C-type filters are connected in series or parallel with the APF to form hybrid filters, whose main purpose is reducing the rating of the APF. In this paper, the C-type filter based LCFL filter is an indivisible component of the SAPF, and it plays an important role in sweeping out the switching harmonic from the SAPF output current.

From the point of view of functionality, the LCFL filter is a kind of selective passive damped LCL filter. Initially, it was designed mainly for reducing the power losses generated by the damping resistor. The LC branch resonant frequency of the C-type filter is tuned at the switching frequency. Therefore, it can bypass most of the switching harmonic currents and significantly reduce the current flow though the damping resistor. Within other frequency ranges, the damping resistor can provide sufficient damping to alleviate resonance and make the system stable. Unlike the methods shown in Fig. 1, this kind of "selective damping" is effective in reducing power losses at the switching frequency. Theoretical analyses have shown that the LCFL filter exhibits excellent switching harmonic attenuation performance. Comparisons with the LCL filter have been presented in this paper. It can be seen that a SAPF with the proposed LCFL filter has better output current quality than a SAPF with the traditional single resistor damped LCL filter.

As a passive damping method, the LCFL filter inevitably has some drawbacks in terms of power efficiency and hardware costs when compared with the active damping methods. Although they have been reduced by the selective damping, there are still some passive damping power losses along with the LCFL filter, which will degrade the overall efficiency of the SAPF. On the other hand, the extra passive components may increase the overall weight and hardware cost. However, it should be noted that the active damping methods may not be economical. As previously mentioned, they may need some extra sensors and control algorithms, which will increase the costs in terms of both hardware and software.

This paper is organized as follows. In Section II, the proposed system configuration is briefly described. In Section III, the principle of the LCFL filter is analyzed, and its design procedure is presented. Section IV describes the main control schemes of the SAPF. Simulation and experimental results are provided in Section V and Section VI, respectively. Finally, conclusions are given in Section VII.

\section{SYSTEM CONFIGURATION DESCRIPTION}

Fig. 2 shows a system configuration diagram of the proposed three-phase three-wire SAPF. The LCFL filter is connected between the SAPF converter and the AC grid. It should be noted that the C-type filter branches of the LCFL filter are connected in delta configuration, which is quite convenient for low voltage application situations. The topology of the traditional passive damped LCL filter is also shown in Fig. 2, which will be used for comparison with the LCFL filter. A three phase diode uncontrolled rectifier with a RL-type dc side load acts as a typical nonlinear load, which will generate a large amount of $(6 n \pm 1)$ th characteristic harmonic currents. The system parameters for the simulation and experiment are listed in Table I.

The SAPF senses the three phase voltages $v_{g} a, b, c$ of the point of common coupling (PCC) for system synchronization. The angular frequency $\omega$ and phase angle $\theta_{g}$ of the fundamental 


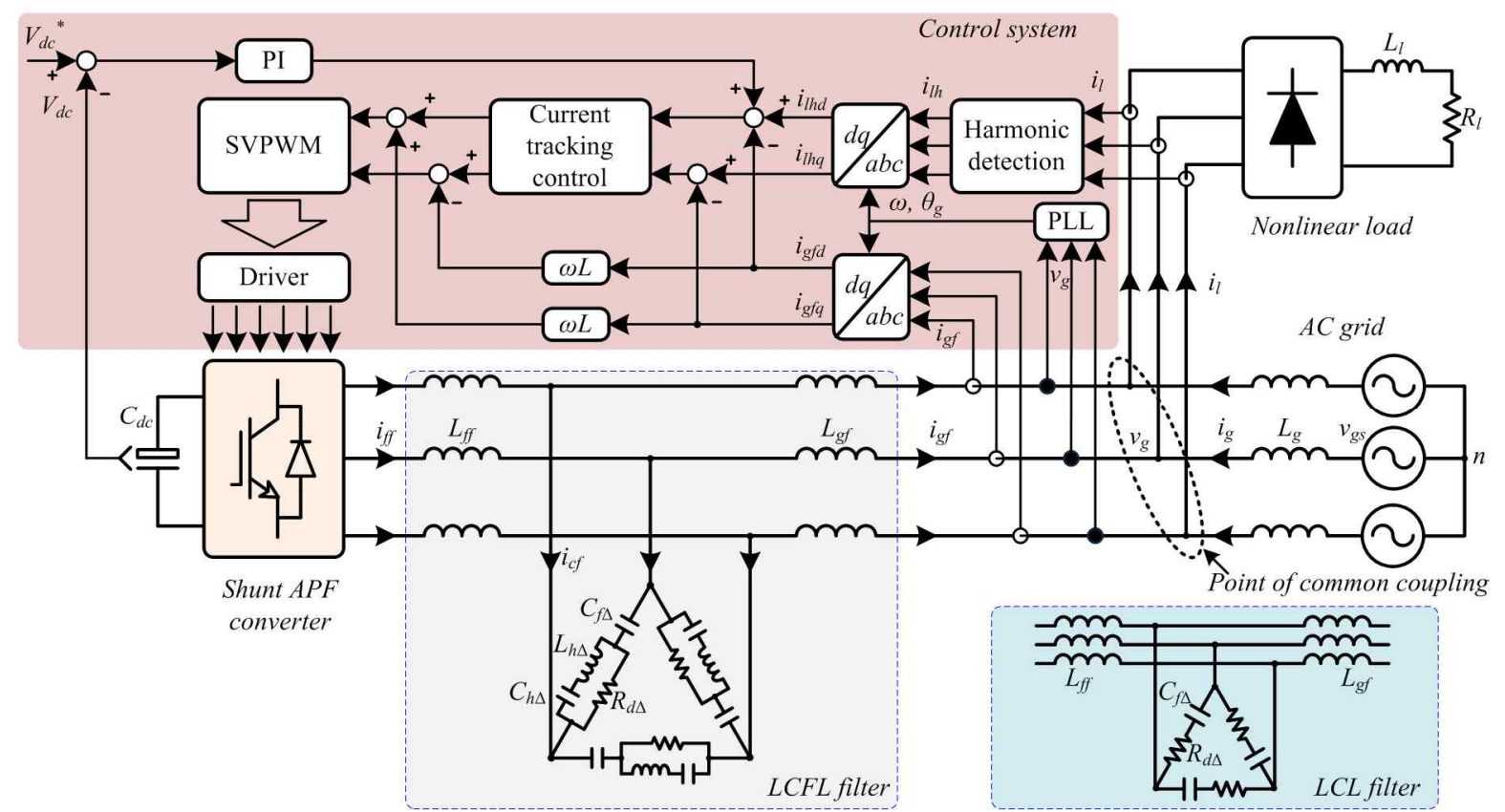

Fig. 2. Configuration diagram of SAPF with output filter in a three-phase three-wire system.

TABLE I

SYSTEM PARAMETERS

\begin{tabular}{|c|c|c|}
\hline Subsystems & Quantity & Values \\
\hline \multirow{3}{*}{ AC Grid } & Grid voltage $V_{g}$ & $380 \mathrm{~V}$ \\
\hline & Line frequency $f_{n}$ & $50 \mathrm{~Hz}$ \\
\hline & Grid impedance $L_{g}$ & $100 \mu \mathrm{H}$ \\
\hline \multirow{3}{*}{$\begin{array}{c}\text { SAPF } \\
\text { converter }\end{array}$} & Nominal power & $66 \mathrm{kVA}$ \\
\hline & Switching frequency $f_{s}$ & $9.6 \mathrm{kHz}$ \\
\hline & DC bus voltage $V_{d c}$ & $700 \mathrm{~V}$ \\
\hline \multirow{6}{*}{$\begin{array}{c}\text { LCFL Filter } \\
\text { (delta } \\
\text { connection) }\end{array}$} & Grid side inductor $L_{g f}$ & $100 \mu \mathrm{H}$ \\
\hline & Converter side inductor $L_{f f}$ & $200 \mu \mathrm{H}$ \\
\hline & Filter capacitor $C_{f \Delta}$ & $6 \mu \mathrm{F}$ \\
\hline & LC branch inductor $L_{h \Delta}$ & $270 \mu \mathrm{H}$ \\
\hline & LC branch capacitor $C_{h \Delta}$ & $1 \mu \mathrm{F}$ \\
\hline & Damping resistor $R_{d \Delta}$ & $7.5 \Omega$ \\
\hline \multirow{4}{*}{$\begin{array}{c}\text { LCL Filter } \\
\text { (delta } \\
\text { connection) }\end{array}$} & Grid side inductor $L_{g f}$ & $100 \mu \mathrm{H}$ \\
\hline & Converter side inductor $L_{f f}$ & $200 \mu \mathrm{H}$ \\
\hline & Filter capacitor $C_{f \Delta}$ & $6 \mu \mathrm{F}$ \\
\hline & Damping resistor $R_{d \Delta}$ & $7.5 \Omega$ \\
\hline \multirow{2}{*}{$\begin{array}{c}\text { Nonlinear } \\
\text { load }\end{array}$} & DC-link inductor $L_{l}$ & $0.5 \mathrm{mH}$ \\
\hline & DC-link resistor $R_{l}$ & $7.5 \Omega$ \\
\hline
\end{tabular}

voltage are extracted by the phase locked loop (PLL). Three phase nonlinear load currents $i_{l a, b, c}$ are sensed by current transformers (CT) to extracted the harmonic current references, and the grid side output currents of the SAPF $i_{g f} a, b, c$ are detected as feedbacks of the close-loop output current control.

The control scheme of the SAPF is also shown in Fig. 2. The harmonic current reference is extracted from the nonlinear load current. Firstly, the fundamental component is calculated by the recursive discrete Fourier transform (RDFT) algorithm [34], and then the harmonic current reference is obtained by simply subtracting the fundamental component from the nonlinear load current. The dc bus voltage of the SAPF converter is regulated the by a PI controller, which forms the outer loop of the control system. The output current tracking control is the inner loop, which is implemented by detecting the grid-side inductor current of the SAPF, and then taking it as a feedback signal of the close-loop current control. The current tracking control is mainly implemented in the fundamental synchronous rotating frame (SRF). A detailed description of the harmonic detection algorithm and output current control scheme will be presented in Section IV.

\section{PRINCIPLE AND DESIGN OF THE LCFL FILTER}

Fig. 3(a) shows the single-phase equivalent topology of the proposed LCFL filter that is shown in Fig. 2. For comparison, the traditional passive damped LCL filter is shown in Fig. 3(b). It must be noted that the parameters relationship between the LCFL filters shown in Fig. 3 and Fig. 2 must follow the Y- $\Delta$ transformation principle, which is: $C_{f}=C_{f \Delta} \times 3, R_{d}=R_{d \Delta} / 3$, $L_{h}=L_{h \Delta} / 3$, and $C_{h}=C_{h \Delta} \times 3$.

\section{A. C-Type Filter}

The C-type filter is in the dashed line box shown in Fig. 3(a), where $Z_{C F}$ is the impedance of the C-type filter, which can be written as:

$$
Z_{C F}=\frac{L_{h} C_{h} C_{f} R_{d} s^{3}+L_{h} C_{h} s^{2}+\left(C_{f}+C_{h}\right) R_{d} s+1}{L_{h} C_{h} C_{f} s^{3}+C_{h} C_{f} R_{d} s^{2}+C_{f} s}
$$

For the passive damped LCL filter shown in Fig. 3(b), the impedance of its $\mathrm{RC}$ series branch $Z_{R C}$ can be written as:

$$
Z_{R C}=\frac{R_{d} C_{f} s+1}{C_{f} s}
$$




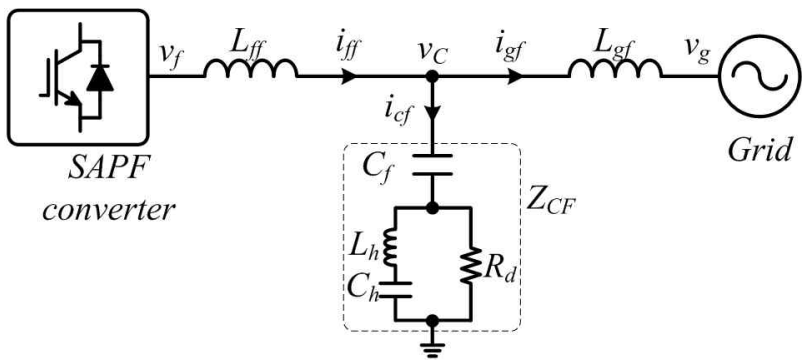

(a)

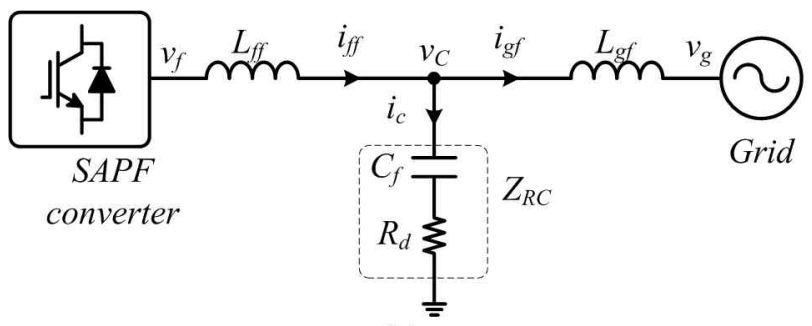

(b)

Fig. 3. Single-phase equivalent topologies of SAPFs with (a) the proposed LCFL filter, and (b) the traditional LCL filter.

The impedance characteristic curves of the C-type filter and the RC filter can be plotted as shown in Fig. 4 based on (1) and (2), respectively. It can be seen from the magnitude curves that the impedance magnitude of the C-type filter approaches that of the RC filter in the low frequency and high frequency ranges, when they both have the same parameters for $C_{f}$ and $R_{d}$. However, the impedance magnitude of the C-type filter around the resonant frequency is much lower than that of the RC filter. This difference is caused by the $L_{h}-C_{h}$ series resonant branch, whose impedance is nearly zero at its resonant frequency. Such an impedance characteristic gives the C-type filter better selective harmonic filtering performance around the resonant frequency $f_{L C}$, which can be calculated as:

$$
f_{L C}=\frac{1}{2 \pi \sqrt{L_{h} C_{h}}} .
$$

\section{B. Model of the LCFL Filter}

Based on the single phase equivalent topology shown in Fig. 3(a), the plant model of the LCFL filter can be represented as shown in Fig. 5. The transfer function from the SAPF converter output voltage $v_{f}$ to the LCFL filter grid side current $i_{g f}$ in the frequency domain can be written as (4), as shown at the bottom of this page.

The transfer function of the LCL filter can be written as:

$$
\frac{i_{g f}}{v_{f}}=\frac{C_{f} R_{d} s+1}{L_{f f} L_{g f} C_{f} s^{3}+\left(L_{f f}+L_{g f}\right) C_{f} R_{d} s^{2}+\left(L_{f f}+L_{g f}\right) s}
$$

where $R_{d}$ is the damping resistance value of the LCL filter. $R_{d}=0$ when it is undamped.

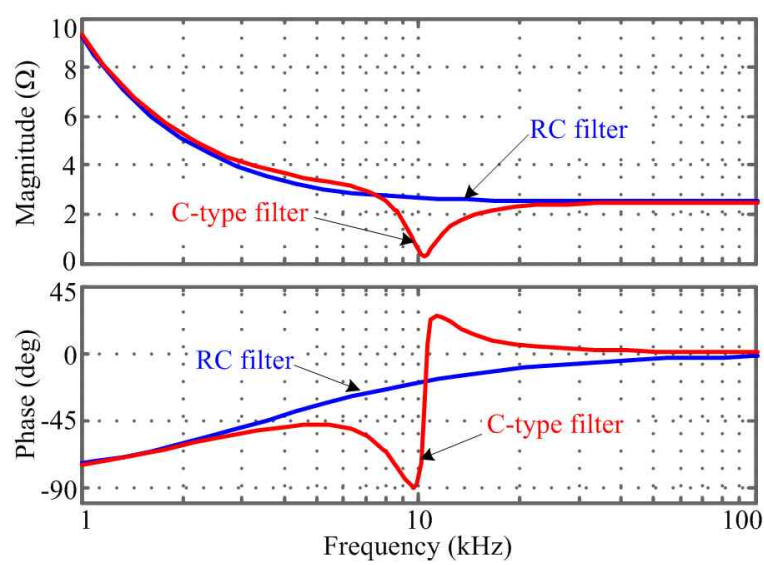

Fig. 4. Impedance characteristics of the C-type filter and RC filter as shown in Fig. 3.

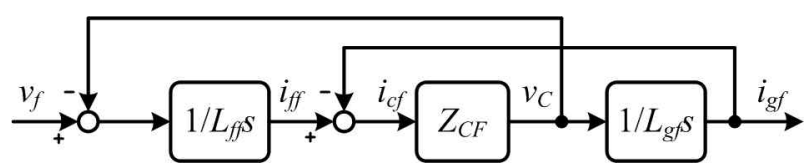

Fig. 5. Plant model of the proposed LCFL filter.

Bode diagrams of (4) and (5) are plotted as shown in Fig. 6. The corresponding curve of an L-filter is drawn in Fig. 6, with an inductance value of:

$$
L=L_{f f}+L_{g f}=300(\mu H) .
$$

Comparing the curves shown in Fig. 6, it can be seen that the magnitude responses of the LCFL filter and LCL filter approach that of the L-filter at the frequency range below 2.5 $\mathrm{kHz}$, which means that both the LCFL filter and LCL filter can be simplified as an inductor in the low frequency range. However, their magnitude responses are quite different at the frequency range above $4.59 \mathrm{kHz}$, especially at around the switching frequency of $9.6 \mathrm{kHz}$. As shown in Fig. 6, the slope rate of the magnitude curve of the L-filter is $-20 \mathrm{~dB} / \mathrm{dec}$, and the corresponding slope rate of the un-damped LCL filter is -60 $\mathrm{dB} / \mathrm{dec}$, which indicates that the un-damped LCL filter has better switching harmonic attenuation capability than the L-filter with the same output inductance. However, a resonant peak at a frequency of $4.59 \mathrm{kHz}$ can be spotted in the magnitude curve of the undamped LCL filter, which may impact the system stability. Simply adding a damping resistor in series with the filter capacitor alleviates the resonant peak, but the slope rate of the magnitude curve of the damped LCL filter will be degraded to about $-40 \mathrm{~dB} / \mathrm{dec}$.

$$
\frac{i_{g f}}{v_{f}}=\frac{R_{d} L_{h} C_{h} C_{f} s^{3}+L_{h} C_{h} s^{2}+\left(C_{f}+C_{h}\right) R_{d} s+1}{L_{f f} L_{g f} L_{h} C_{h} C_{f} s^{5}+\left(L_{f f} L_{g}+L_{f f} L_{h}+L_{g f} L_{h}\right) C_{f f} C_{h} R_{d} s^{4}+\left(L_{f f} L_{g f} C_{f}+L_{f f} L_{h} C_{h}+L_{g f} L_{h} C_{h}\right) s^{3}+\left(L_{f f}+L_{g f}\right)\left(C_{f}+C_{h}\right) R_{d} s^{2}+\left(L_{f f}+L_{g f}\right) s}
$$




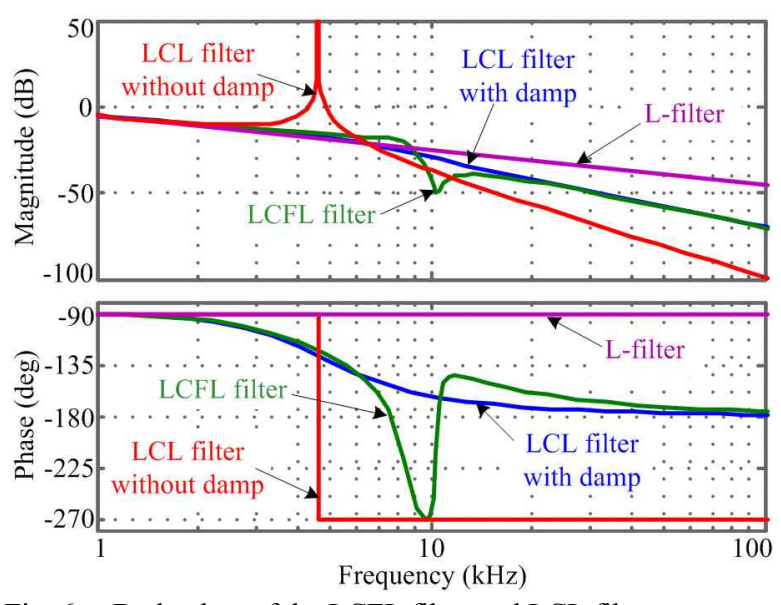

Fig. 6. Bode plots of the LCFL filter and LCL filters.

Examining the magnitude curve of the proposed LCFL filter, the green line shown in Fig. 6, it can be seen that its magnitude value around the switching frequency $9.6 \mathrm{kHz}$ is even lower than that of the undamped LCL filter, which indicates the excellent switching frequency harmonic attenuation capability of the LCFL filter. Moreover, no resonant peak can be spotted around the resonant frequency $f_{\text {res }}$, which means that the LCFL filter can damp the resonance problem effectively. It can be concluded from the Bode plots shown in Fig. 6 that the LCFL filter has better switching harmonic alleviation ability than the LCL filter and the L-filter.

From a topology point of view, the LCFL filter can be obtained by simply adding an LC branch connected in parallel with the damping resistor of a passive damped LCL filter. This LC branch series resonance frequency is tuned at the switching frequency, so it provides a low impedance path for the switching harmonic current and significantly reduces that flow through the damping resistor. Therefore, the power losses of the damping resistor of the LCFL filter can be significantly reduced. On the other hand, for the passive damped LCL filter, all of the switching harmonic current that is filtered by the capacitor will also flow through the damping resistor, which produces a large amount of the power losses. Compared to the traditional LCL filter, the LCFL filter proposed in this paper can provide better switching ripple attenuation capability. In addition, it reduces the power losses of the damping resistor.

\section{Design of the LCFL Filter}

The LCFL filter can be designed by the following step-bystep design procedure.

1) Select the output inductors $L_{f f}$ and $L_{g f}$.

The total output inductance cannot be too high, since it will increase the voltage drop along the inductor and affect the reference current tracking ability of the SAPF. However, if the output inductance is too small, its current ripple attenuation performance may be degraded. The Appendix shows the method to determine the total output inductance, and it obtains the value range as:

$$
208 \mu H \leq L \leq 555 \mu H .
$$

A relatively small inductance value was chosen for better dynamic response of the SAPF, with $L=300 \mu \mathrm{H}$. The converter side inductor was set to $L_{f f}=200 \mu \mathrm{H}$ and the grid side inductor was set to $L_{g f}=100 \mu \mathrm{H}$.

2) Determine the filter capacitor $C_{f}$.

The resonance frequency of the output filter of the SAPF must satisfy the constraint of:

$$
\frac{f_{\max }}{0.3} \leq f_{\text {res }}=\frac{1}{2 \pi} \sqrt{\frac{L_{f f}+L_{g f}}{L_{f f} L_{g f} C_{f}}} \leq \frac{f_{s w}}{2}
$$

where $f_{\max }$ is highest frequency of harmonic current that needs to be compensated by the SAPF, and $f_{s w}$ is the switching frequency of the SAPF converter.

Therefore, the value range of the filter capacitance $C_{f}$ can be calculated from (8) as:

$$
16.5 \mu F \leq C_{f} \leq 21.9 \mu F \text {. }
$$

The filter capacitance was chosen as $C_{f}=18 \mu \mathrm{F}$, and the resonant frequency was verified by:

$$
f_{\text {res }}=\frac{1}{2 \pi} \sqrt{\frac{L_{f f}+L_{g f}}{L_{f f} L_{g f} C_{f}}}=\frac{10^{6}}{2 \pi \sqrt{66.6 \times 18}}=4.59(\mathrm{kHz}) .
$$

Which falls into the range from 4.17 to $4.8 \mathrm{kHz}$ that is specified by (8).

3) Choose the damping resistor $R_{d}$.

Passive damping must be sufficient to alleviate resonance at a frequency of $f_{\text {res }}$. Meanwhile, its power losses cannot be too high. The damping resistance is set to a value similar to that of the filter capacitor impedance at the resonant frequency, which is:

$$
\left|Z_{C f}\right|_{f_{\text {res }}}=\frac{1}{2 \pi f_{\text {res }} C_{f}} \approx 1.93(\Omega) \text {. }
$$

The damping resistor was chosen as $R_{d}=2.5 \Omega$.

4) Choose the LC series branch $L_{h}$ and $C_{h}$.

The series resonant frequency of the LC branch must be tuned at around the switching frequency to bypass the switching current, which can be calculated as:

$$
f_{L C}=\frac{1}{2 \pi \sqrt{L_{h} C_{h}}} \approx 9.6(\mathrm{kHz}) .
$$

First, the LC branch capacitance is chosen as $C_{h}=3 \mu \mathrm{F}$, and then the LC branch inductance can be calculated from (12) as $L_{h} \approx 90 \mu \mathrm{H}$.

5) Y- $\Delta$ transformation parameter calculation.

The calculation given above is based on the single equivalent circuit shown in Fig. 3, which corresponds to the star-connection of the C-type filter in a three phase system. Since the C-type filters are connected in the delta configuration, as shown in Fig. 2, the parameters must be adjusted to get the expected performance. Based on the Y- $\Delta$ transformation principle, the delta-connected LCFL filter parameters are eventually determined, as shown in Table I: 
$L_{f f}=200 \mu \mathrm{H}, L_{g f}=100 \mu \mathrm{H}, C_{f \mathrm{~A}}=C_{f} / 3=6 \mu \mathrm{F}, R_{d \Delta}=R_{d} \times 3=7.5 \Omega$,

$L_{h \Delta}=L_{h} \times 3=270 \mu \mathrm{H}$, and $C_{h \Delta}=C_{h} / 3=1 \mu \mathrm{F}$.

\section{CONTROL SCHEME OF THE SAPF}

\section{A. Mathematical Model of the SAPF}

Based on the previous analysis, it can be seen the LCFL filter behaves like an inductor at the low frequency range below $2.5 \mathrm{kHz}$. For harmonic compensation of the SAPF, the common requirement of its output current is upon to the 50th harmonic, which means that only the frequency range below $2.5 \mathrm{kHz}$ needs to be considered while designing the control system. As a result, it is reasonable to simplify the LCFL filter as an inductor in low frequency range, whose inductance value is determined by (6). Therefore, the main circuit of the three-phase three-wire SAPF in the low frequency range can be simplified as shown as Fig. 7.

Based on the KVL principle, the differential equations that describe the SAPF output current and voltage relationship is:

$$
\left\{\begin{array}{l}
L \frac{d i_{a}}{d t}=v_{g a}-i_{a} R-v_{f a} \\
L \frac{d i_{b}}{d t}=v_{g b}-i_{b} R-v_{f b} \\
L \frac{d i_{c}}{d t}=v_{g c}-i_{c} R-v_{f c}
\end{array}\right.
$$

where, $v_{g a, b, c}$ are the PCC voltages, $v_{f a, b, c}$ are the output voltages of the SAPF, and $i_{a, b, c}$ are the output currents of the SAPF. $L=L_{a}=L_{b}=L_{c}=300 \mu \mathrm{H}$ is the output inductance, and $R$ is the equivalent series resistance (ESR) of the output inductor.

Equation (13) can be expressed in the d-q SRF by the synchronous rotating transformation, which yields:

$$
\left\{\begin{array}{l}
L \frac{d i_{d}}{d t}=v_{g d}-i_{d} R+\omega L i_{q}-v_{f d} \\
L \frac{d i_{q}}{d t}=v_{g q}-i_{q} R-\omega L i_{d}-v_{f q}
\end{array}\right.
$$

which is the mathematical model of the three-phase three-wire SAPF in the d-q SRF.

\section{B. RDFT Based Harmonic Current Extraction Algorithm}

The RDFT algorithm is suitable for extracting each harmonic component from a periodical signal, which will be used for the harmonic current extraction of the SAPF. The principle of the RDFT algorithm can be described as follows:

Assume a periodic signal $x(t)$ with a time period $T$, then it can be expressed as the sum of its harmonic components as:

$$
x(k \tau)=\sum_{h=1}^{N_{m}} A_{h} \cos (h \omega k \tau)+\sum_{h=1}^{N_{m}} B_{h} \sin (h \omega k \tau)
$$

where, $h$ is the harmonic order, $N_{m}$ is the maximum harmonic order to be considered, $\omega$ is the fundamental angular frequency, $N$ is the sampling number in a fundamental period, $\tau=T / N$ is the sampling interval time, and $A_{h}$ and $B_{h}$ are the amplitudes of the real and imaginary components of the $h$ th harmonic.

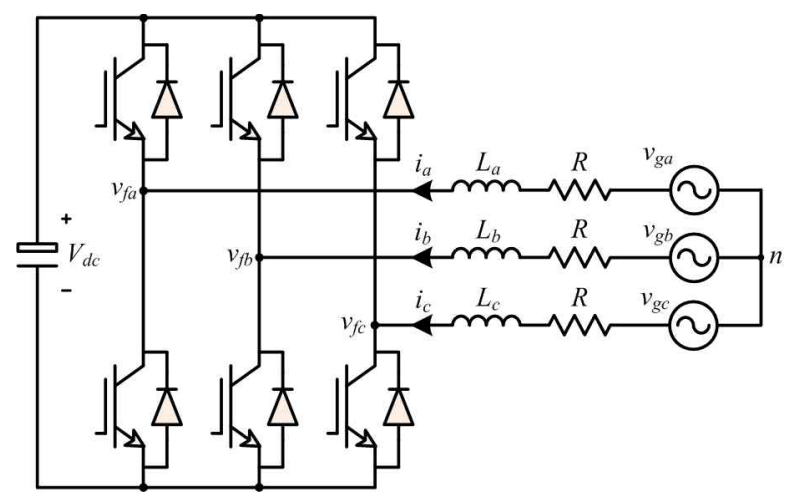

Fig. 7. Simplified main circuit of the three-phase three-wire SAPF at low frequency range.

Now the fundamental component can be considered. At each sampling interval, the amplitudes of the real and imaginary components can be calculated in real-time using the latest $N$ sampled values of the $x(t)$, as follows:

$$
\left\{\begin{array}{l}
A_{1}(k)=\frac{2}{N} \sum_{i=k}^{k-N+1} x(i \tau) \cos (\omega i \tau) \\
B_{1}(k)=\frac{2}{N} \sum_{i=k}^{k-N+1} x(i \tau) \sin (\omega i \tau)
\end{array}\right.
$$

where, $k$ represents the newest sample point.

However, equation (16) is hard to implement in a DSP, because each calculation needs the latest $N$ sampled values of the input signal, which will take the DSP a large amount of resources and make it unpractical for SAPF application. However, (16) can be expressed in a recursive way as follows:

$$
\left\{\begin{array}{l}
A_{1}(k)=A_{1}(k-1)+\frac{2}{N}[x(k \tau)-x((k-N) \tau)] \cos (\omega k \tau) \\
B_{1}(k)=B_{1}(k-1)+\frac{2}{N}[x(k \tau)-x((k-N) \tau)] \sin (\omega k \tau)
\end{array}\right.
$$

Substituting (17) into (15), the fundamental component can be obtained as:

$$
x_{1}(k \tau)=A_{1}(k) \cos (\omega k \tau)+B_{1}(k) \sin (\omega k \tau)
$$

In this paper, the periodical signal is the nonlinear load current $i_{l}$. Using the RDFT algorithm described above, the fundamental current can be extracted from the nonlinear load current, and then the harmonic current can be obtained by subtracting the fundamental component from the nonlinear load current. The application of the RDFT can eliminate the requirement of low-pass filters in the d-q frame, and it exhibits several merits such as a fast transient response speed and excellent steady-state accuracy [34].

\section{SAPF Output Current Tracking Control}

The SAPF output current tracking control is implemented in the $d-q$ frame. Since the main components of the output currents of the SAPF are harmonic currents, they are still ac quantities after the fundamental synchronous rotating transform. The traditional PI controller cannot ensure zero steady-state error tracking to the ac signals. As a result, the repetitive controller is considered, and its structure is shown in Fig.8. 


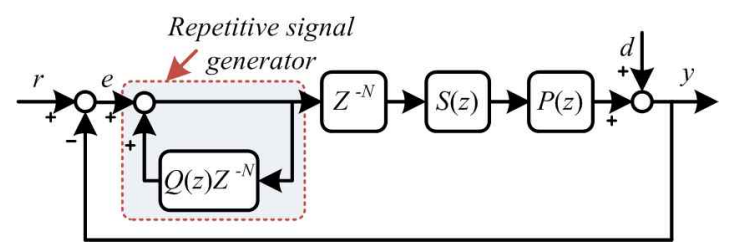

Fig. 8. Diagram of repetitive controller.

The repetitive controller is based on the internal mode principle. A repetitive signal generator is inserted into the control loop, as shown in Fig. 8, and acts as the internal mode of the input signal. The repetitive controller can ensure perfect tracking to a periodic signal with zero steady-state error. However, its dynamic response is not very fast. In this paper, a PI controller and a repetitive controller are put in parallel in the SAPF output current control system, to guarantee both the current tracking dynamic response speed and steady-state accuracy [35].

\section{SimUlation RESUlTS}

Simulation of the LCFL-filter-based SAPF was conducted with Matlab/Simulink software, based on the system configuration shown in Fig. 1 and the parameters listed in Table I.

Fig. 9 shows the harmonic compensation steady-state simulation results of the LCFL-filter-based SAPF. Fig. 9(a) shows the nonlinear load current $i$, whose THD is $29.33 \%$. Fig. 9(b) shows the grid current $i_{g}$, whose THD is reduced to $4.42 \%$ after harmonic compensation by the SAPF. Fig. 9(c) presents the output compensation current $i_{g f}$ of the SAPF, which is the grid side inductor current of the LCFL filter.

Fig. 10 shows the waveforms and spectrums of the currents that flow through the different components of the LCFL filter. It can be seen in Fig. 10(a) that the converter side current contains a lot of switching ripples. However, they are mostly absorbed by the C-type filter, as shown as Fig. 10(b). The unwanted switching ripple currents injected into the grid are thus significantly reduced. This can be reflected in the waveform and spectrum of the grid side inductor current as shown as Fig. 10(c).

Fig. 11 presents the currents that flow through the damping resistors of the LCFL filter and LCL filter. It can be seen from the magnitude spectrum of Fig. 11(a) that there is almost no switching frequency harmonic component in the damping resistor current of the LCFL filter. The RMS value of the damping resistor current of the LCFL filter is 1.92A. Therefore, the damping resistor power loss can be calculated as $1.92^{2} \times 7.5=27.6(\mathrm{~W})$. The RMS value of the damping resistor current of the LCL filter is $4.39 \mathrm{~A}$, and the corresponding power loss is $4.39^{2} \times 7.5=144.5(\mathrm{~W})$. It can be seen that the damping resistor power loss of the LCL filter is about 5.2 times larger than that of the LCFL filter. (a)

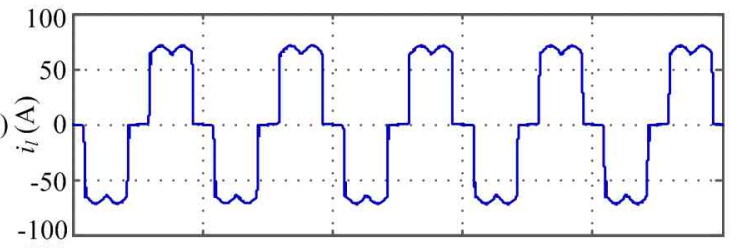

(b)

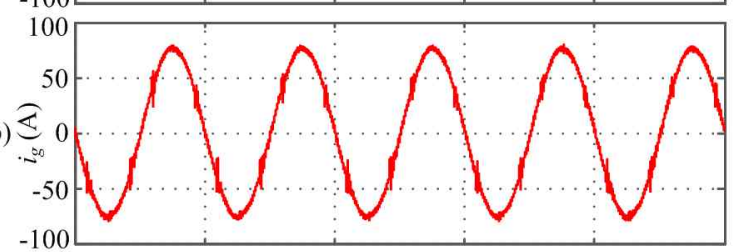

(c)

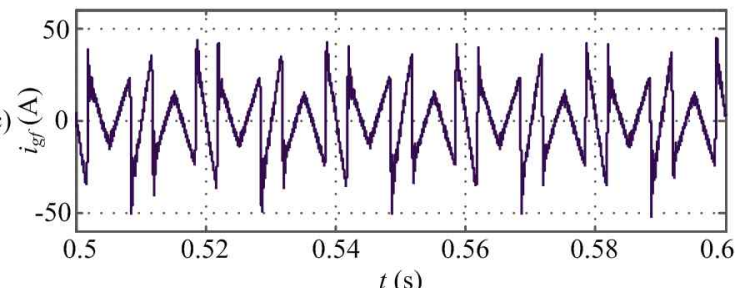

Fig. 9. Steady-state harmonic compensation simulation results of the LCFL-filter-based SAPF. (a) Nonlinear load current. (b) Grid current, and (c) SAPF output current.

\section{EXPERIMENTAL RESULTS}

A $66.6 \mathrm{kVA}$ three-phase three-wire SAPF prototype based on the parameters listed in Table I was built in the laboratory, to validate the theoretical analyses and functionality of the LCFL filter. The control algorithm was implemented in the control board which is based on a TMS320F2812 digital signal processor (DSP). The A/D sampling frequency is set at $9.6 \mathrm{kHz}$, which is the same as the switching frequency of the SAPF converter.

Fig. 12 shows the harmonic compensation steady-state experimental results of the LCFL-filter-based SAPF. Fig. 12(a) shows the nonlinear load current waveform that contains a large amount of harmonic current, and whose THD is $28.43 \%$. Fig. 12(b) shows the grid current after harmonic compensation by the SAPF, where the THD is reduced to $4.83 \%$. Fig. 12(c) presents the output current of the SAPF, which is also the grid side current of the LCFL filter.

Fig. 13 shows the currents that flow through the different components of the LCFL filter. Fig. 13(a) shows the converter-side inductor current, which contains a large amount of switching ripple. Fig. 13(b) shows the current absorbed by the C-type filter branch, whose main component is the switching harmonic current generated by the SAPF converter. Fig. 13(c) shows the grid-side inductor current. It can be seen that its waveform quality is much better than that of the converter-side inductor current.

Fig. 14 compares the spectrums of the grid-side inductor currents of both the LCFL filter and LCL filter based SAPF. It can be clearly seen that the harmonic current magnitude around the switching frequency of the LCFL-filter-based SAPF is 
(a)

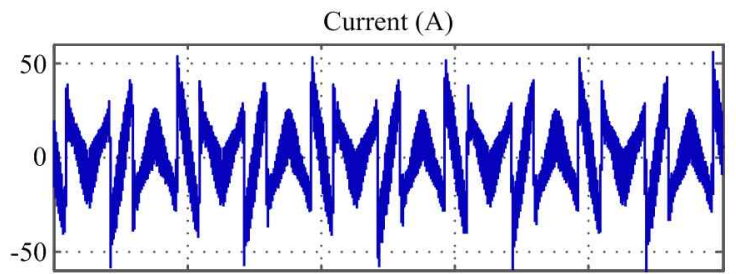

(b)

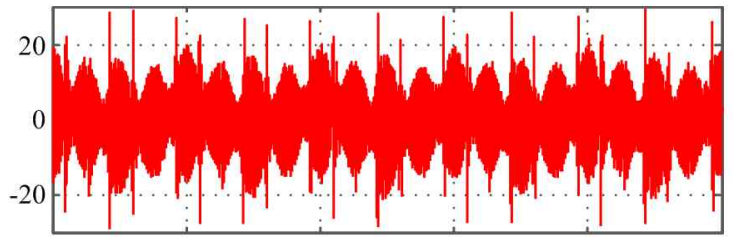

(c)

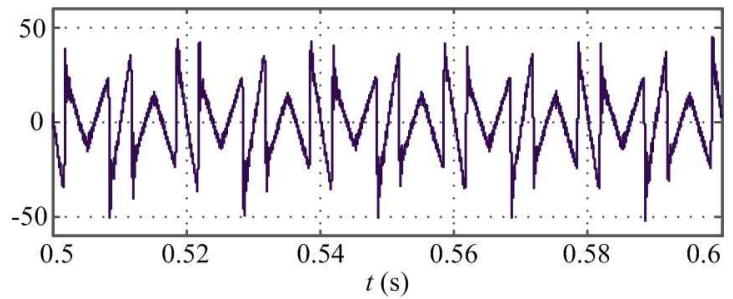

Magnitude (A)
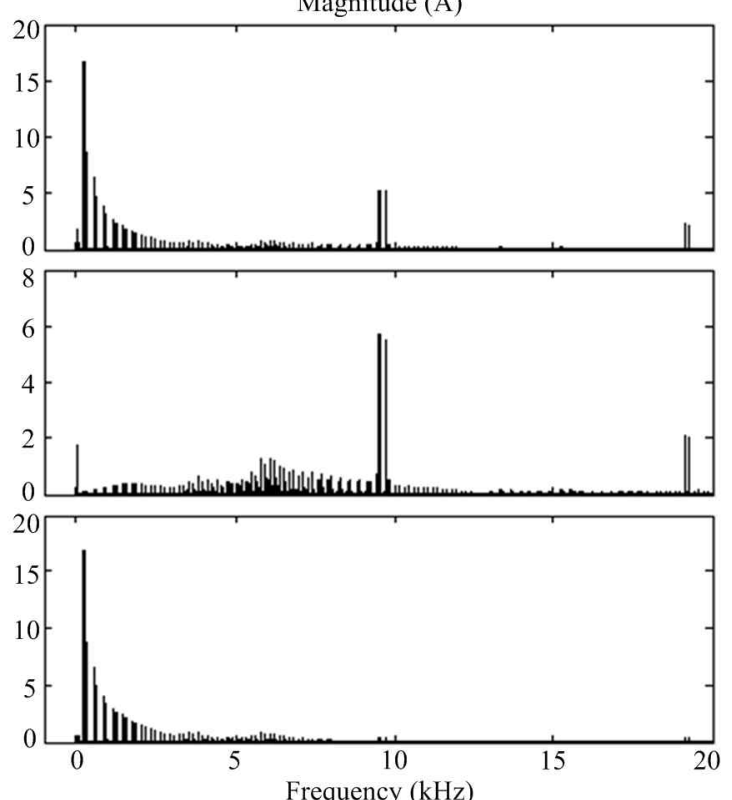

Fig. 10. Simulation waveform and spectrum of current that flow through different components of the LCFL-filter: (a) converter side inductor current, (b) C-type filter branch current, and (c) grid side inductor current.
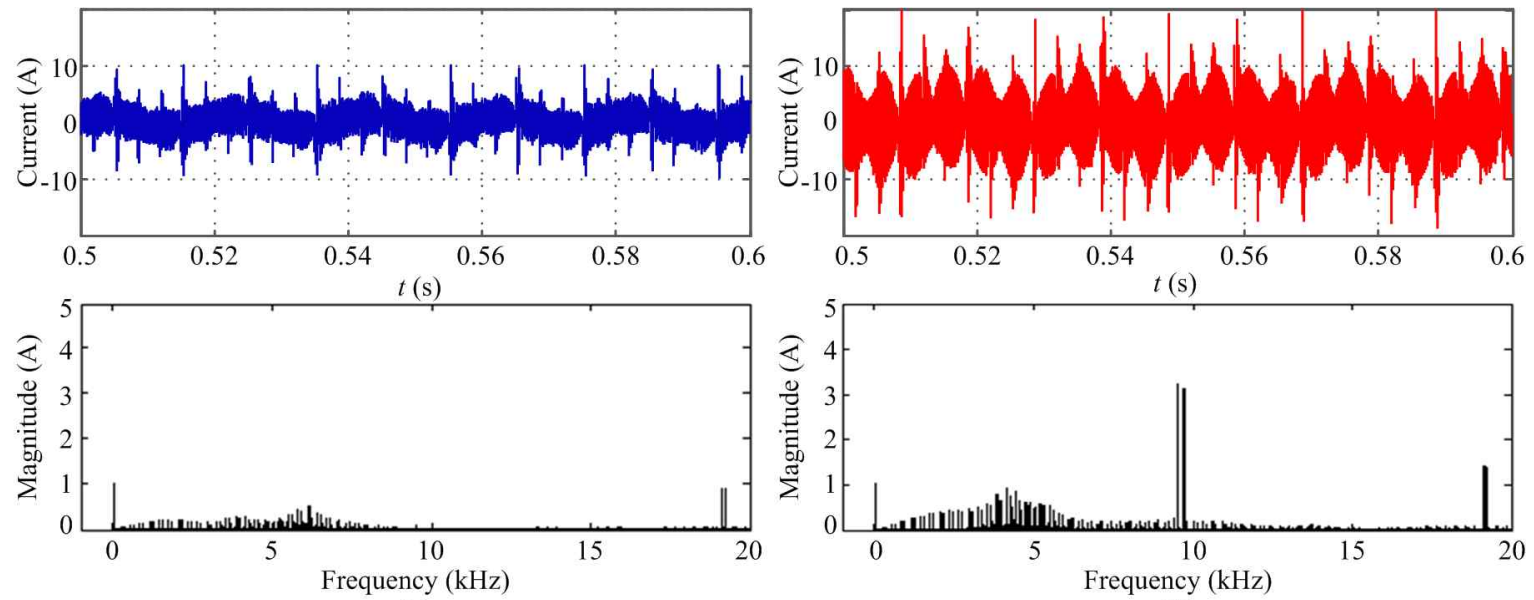

(a)

(b)

Fig. 11. Simulation waveform and magnitude spectrum of damping resistor current (a) the LCFL filter, and (b) the LCL filter.

much lower than that of the LCL-filter-based SAPF, which indicates a better switching harmonic attenuation performance of the LCFL filter.

Fig. 15 shows the currents flowing through the damping resistors of the LCFL filter and LCL filter, which are closely related to the power losses. The RMS value of the current flow through the damping resistor of the LCFL filter is $2.08 \mathrm{~A}$, while its counterpart of the LCL filter is 3.37A. The damping resistor power loss of the LCL filter can be calculated as $3.37^{2} \times 7.5=85.2(\mathrm{~W})$, and the corresponding power loss of the LCFL filter is $2.08^{2} \times 7.5=32.4(\mathrm{~W})$. It can be seen that the damping resistor power loss of the LCFL filter is much less than that of the traditional passive damped LCL filter.

\section{CONCLUSIONS}

This paper proposed and designed an output filter called an LCFL filter for application to a three-phase three-wire SAPF. This LCFL filter is derived from a traditional LCL filter by replacing its capacitor with a C-type filter, and then constructing an L-C-type filter-L (LCFL) topology. Theoretical analyses have shown that the LCFL filter can provide better switching harmonic attenuation than the traditional passive damped LCL filter. Furthermore, since the switching harmonic currents are mostly bypassed by the LC series branch of the C-type filter, the damping resistor power loss can be significantly reduced when compared to the passive damped LCL filter. The principle and parameter design of the LCFL 
(a)

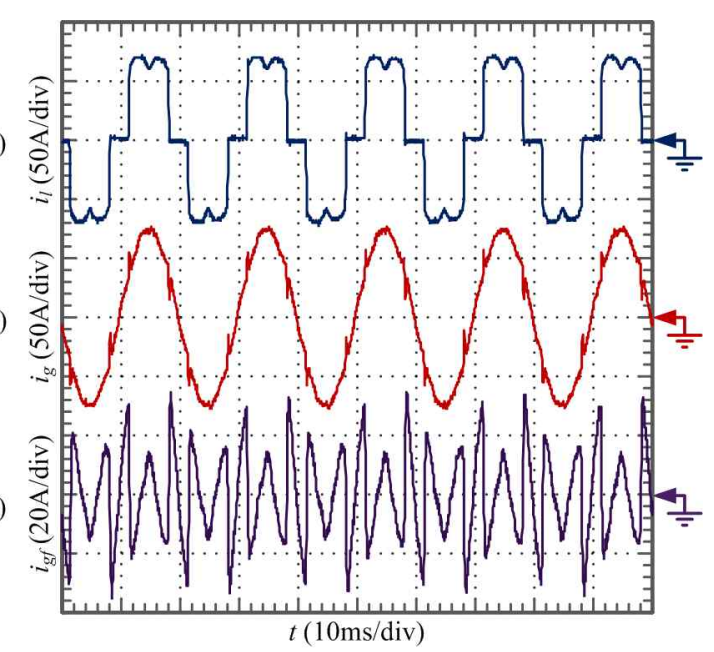

Fig. 12. Harmonic compensation steady-state experimental results of the LCFL-filter-based SAPF: (a) nonlinear load current, (b) grid current, and (c) SAPF output current.

(a)

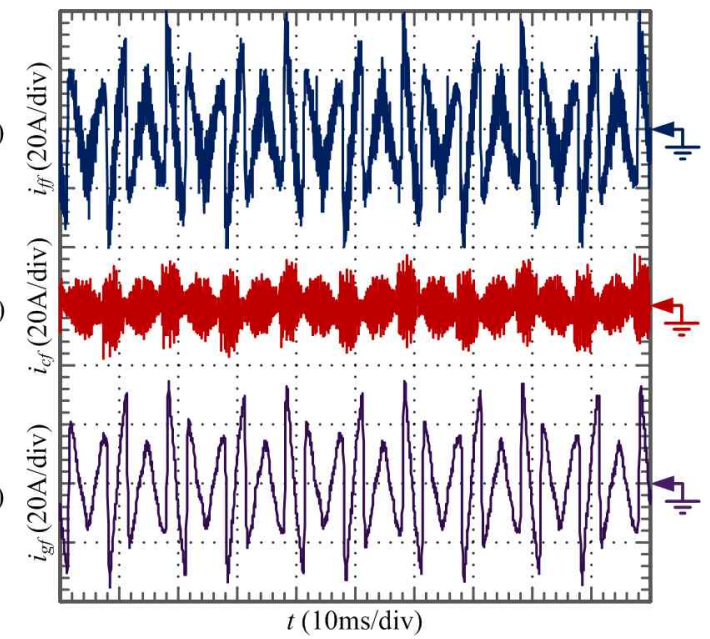

Fig. 13. Experimental results of current waveform that flow through different components of the LCFL-filter: (a) converter side inductor current, (b) C-type filter current, and (c) grid side inductor current.

filter have been presented, and simulation and experimental results have verified the theoretical analyses as well as the effectiveness of the LCFL filter.

\section{APPENDIX}

\section{SELECTION OF THE OUTPUT INDUCTANCE}

The total output inductor of the LCFL filter must be selected properly to make sure that the SAPF has fast current reference tracking ability and can provide enough ripple attenuation. Take phase A as example, the determination of the output inductance concerns the converter modulation process and can be considered from two aspects as follows.

\section{A. Maximum Output Inductance that Satisfies the Current Reference Tracking Requirement}

To determine the maximum output inductance that satisfies

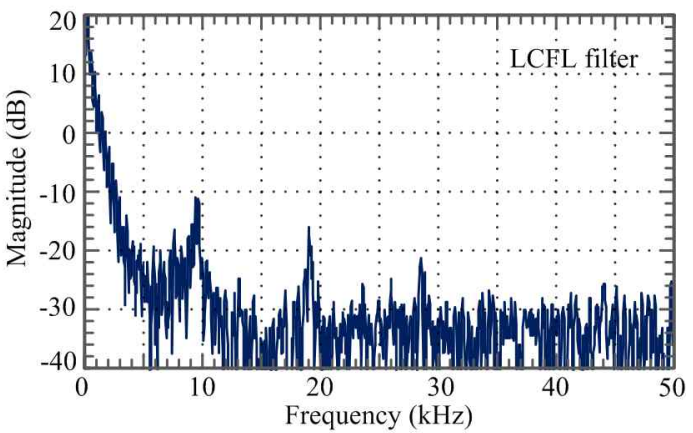

(a)

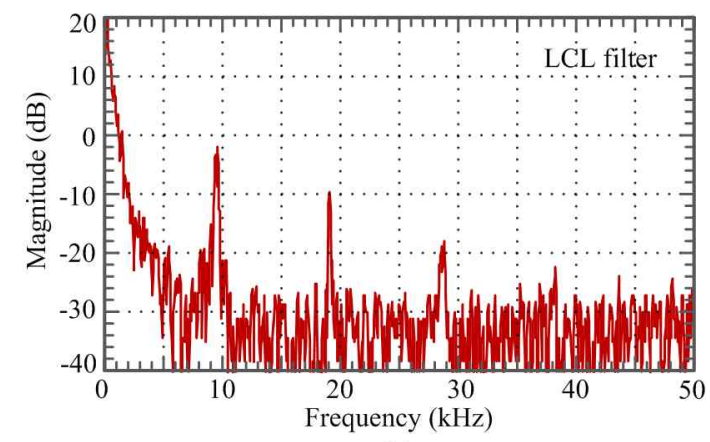

(b)

Fig. 14. Spectrums of the grid side inductor currents of (a) LCFL-filter-based SAPF, and (b) LCL-filter-based SAPF.

(a)

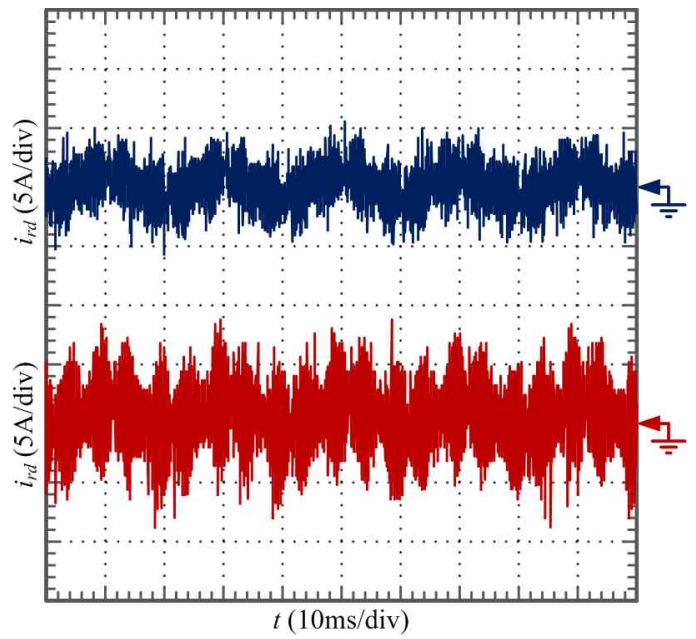

Fig. 15. Currents that flow through the damping resistors of (a) LCFL filter, and (b) LCL filter.

the current tracking requirement, the output inductor current $i_{L \mathrm{a}}$ dynamic waveform is analyzed in a switching period that contains a zero-crossing point as shown as Fig. A1, because the output current change rate commonly has its largest value at around the zero-crossing point.

When $0 \leq t \leq T_{1}, S_{\mathrm{a}}=1$, an equation that describes the current dynamic of phase A can be obtained as:

$$
L \frac{d i_{L a}}{d t}=u_{g a}+\frac{S_{b}+S_{c}}{3} V_{d c}=L \frac{\Delta i_{1}}{T_{1}}
$$

where, $V_{d c}$ is the dc link voltage of the SAPF converter, $L$ is the total output inductance of Phase $\mathrm{A}$, and $\Delta i_{1}$ is current rising 


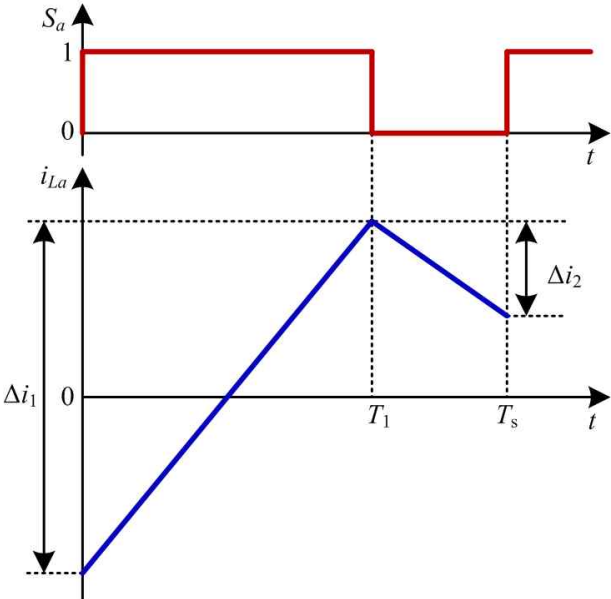

Fig. A1. Output inductor current dynamic waveform of the SAPF in a switching period contains zero-crossing point.

during the time interval of $T_{1} . S_{\mathrm{a}, \mathrm{b}, \mathrm{c}}$ are the switching functions for each phase leg of the SAPF converter, $S=1$ means the upper IGBT is on, and $S=0$ means the lower IGBT is on.

When $T_{1} \leq t \leq T_{s}, S_{\mathrm{a}}=0$, another current dynamic equation can be obtained as:

$$
L \frac{d i_{L a}}{d t}=u_{g a}+\frac{-2+S_{b}+S_{c}}{3} V_{d c}=L \frac{\Delta i_{2}}{T_{s}-T_{1}}
$$

where $T_{s}$ is the switching period of the SAPF converter, and $\Delta i_{2}$ is the current dropping during the time interval of $T_{\mathrm{s}}-T_{1}$.

To satisfy the current reference tracking demand the following inequality must be satisfied:

$$
\frac{\left|\Delta i_{1}\right|-\left|\Delta i_{2}\right|}{T_{s}} \geq \frac{\Delta i_{\max }^{*}}{T_{s}}
$$

where $\Delta i_{\text {max }}^{*}$ is the maximum current reference change value in one switching period.

Considering the extreme case when $S_{b}=S_{c}=0$, the real current change rate in one switching period from (A-1) and (A-2) can be obtained as:

$$
\frac{\left|\Delta i_{1}-\Delta i_{2}\right|}{T_{s}}=\frac{\left|T_{1}\left(2 u_{g a}+2 V_{d c} / 3\right)-T_{s} u_{g a}\right|}{L T_{s}} .
$$

When $T_{1}=T_{\mathrm{s}}$, the maximum current change rate available can be obtained as:

$$
\left.\frac{\left|\Delta i_{1}-\Delta i_{2}\right|}{T_{s}}\right|_{\max }=\frac{u_{g a}+2 V_{d c} / 3}{L} .
$$

Note that:

$$
\frac{\left|\Delta i_{1}-\Delta i_{2}\right|}{T_{s}} \geq \frac{\left|\Delta i_{1}\right|-\left|\Delta i_{2}\right|}{T_{s}} .
$$

Substituting (A-3) and (A-5) into (A-6), the maximum output inductance that satisfies the current reference tracking demand can be obtained as:

$$
L \leq \frac{\left(u_{g a}+2 V_{d c} / 3\right)}{\Delta i_{\max }^{*}} T_{s} .
$$

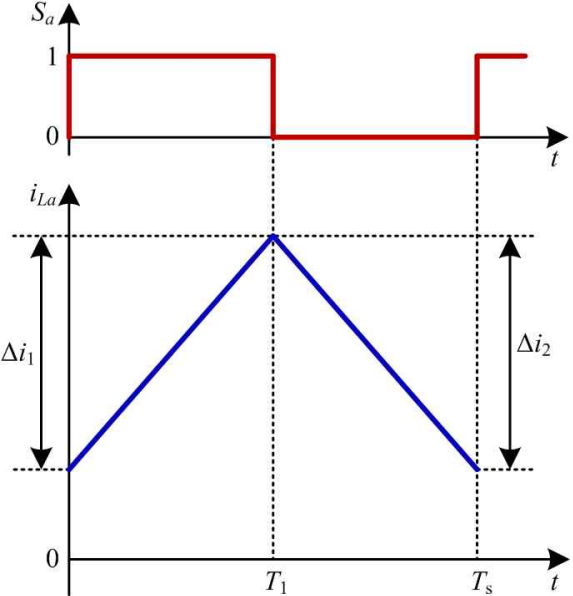

Fig. A2. Output inductor current dynamic waveform of the SAPF in a switching period contains current peak point.

B. Minimum output inductance that satisfies the current ripple alleviation requirement

To determine the minimum output inductance that satisfies the current ripple attenuation requirement, the output inductor current $i_{L \mathrm{a}}$ dynamic waveform can be analyzed in a switching period that contains the current peak value, as shown as Fig. A2, because the output current ripple commonly has its largest value at around the peak point.

When $0 \leq t \leq T_{1}, S_{\mathrm{a}}=1$, the equation that describe the current dynamic of phase A can be obtained as:

$$
L \frac{d i_{L a}}{d t}=u_{g a}+\frac{S_{b}+S_{c}}{3} V_{d c}=L \frac{\Delta i_{1}}{T_{1}} .
$$

When $T_{1} \leq t \leq T_{s}, S_{\mathrm{a}}=0$, another current dynamic equation can be obtained as:

$$
L \frac{d i_{L a}}{d t}=u_{g a}-\frac{2+S_{b}+S_{c}}{3} V_{d c}=L \frac{\Delta i_{2}}{T_{s}-T_{1}} .
$$

Considering the extreme case when $S_{b}=S_{c}=0$, the current rising and dropping values from (A-8) and (A-9) can be calculated as:

$$
\begin{gathered}
\Delta i_{1}=\frac{T_{1} u_{g a}}{L}, \\
\Delta i_{2}=\frac{u_{g a}-2 V_{d c} / 3}{L}\left(T_{s}-T_{1}\right) .
\end{gathered}
$$

Note that the maximum ripple can be obtained when $\left|\Delta i_{1}\right|=\left|\Delta i_{2}\right|$, so we obtain:

$$
\Delta i_{1}+\Delta i_{2}=0 \text {. }
$$

Substituting (A-10) and (A-11) into (A-12), yields:

$$
T_{s}-T_{1}=\frac{u_{g a}}{2 V_{d c} / 3} T_{s} \cdot
$$

By substituting (A-13) into (A-11), the current dropping during time interval $T_{s}-T_{1}$ can be calculated as:

$$
\left|\Delta i_{2}\right|=\frac{u_{g a}-2 V_{d c} / 3}{L} \frac{u_{g a}}{2 V_{d c} / 3} T_{s}=\frac{\left(2 V_{d c}-3 u_{g a}\right) T_{s} u_{g a}}{2 V_{d c} L} .
$$

Let $\left|\Delta i_{2}\right| \leq \Delta i_{\text {ripp }}$, then the minimum output inductance 
that satisfies the current ripple alleviation demand can be obtained as:

$$
L \geq \frac{\left(2 V_{d c}-3 u_{g a}\right) T_{s} u_{g a}}{2 V_{d c} \Delta i_{r i p p}}
$$

where $\Delta i_{\text {ripp }}$ is the maximum ripple current allowed in a switching period.

Based on (A-7) and (A-15), the total output inductance value range can be determined as:

$$
\frac{\left(2 V_{d c}-3 u_{s a}\right) T_{s} u_{s a}}{2 V_{d c} \Delta i_{r i p p}} \leq L \leq \frac{\left(u_{s a}+2 V_{d c} / 3\right)}{\Delta i_{\max }^{*}} T_{s}
$$

where $V_{d c}=700 \mathrm{~V}, u_{g a}=311 \mathrm{~V}, T_{s}=1 / 9600 \mathrm{~s}, \Delta i_{\text {max }}^{*}=100 \sqrt{2} \mathrm{~A}$, and $\Delta i_{\text {ripp }}=20 \mathrm{~A}$. By substituting these parameters into (A-16), the total output inductance value range of the LCFL filter can be obtained as:

$$
208 \mu H \leq L \leq 555 \mu H .
$$

\section{ACKNOWLEDGMENT}

This paper and its related work were supported by the National Natural Science Foundation of China (No.51277086), and the Power Electronics Science and Education Development Program of Delta Environmental \& Educational Foundation (DREK2012001).

\section{REFERENCES}

[1] F. Blaabjerg, Z. Chen, and S. B. Kjaer, "Power electronics as efficient interface in dispersed power generation systems," IEEE Trans. Power Electron., Vol. 19, No. 5, pp. 1184-1194, Sep. 2004.

[2] F. Blaabjerg, R. Teodorescu, M. Liserre, and A. V. Timbus, "Overview of control and grid synchronization for distributed power generation systems," IEEE Trans. Ind. Electron., Vol. 53, No. 5, pp. 1398-1409, Oct. 2006.

[3] Q.-N. Trinh and H.-H. Lee, "Advanced repetitive controller to improve the voltage characteristics of distributed generation with nonlinear loads," Journal of Power Electronics, Vol. 13, No. 3, pp. 409-418, May 2013

[4] J. Rocabert, A. Luna, F. Blaabjerg, and P. Rodríguez, "Control of power converters in AC microgrids," IEEE Trans. Power Electron., Vol. 27, No. 11, pp. 4734-4749, Nov. 2012.

[5] Y. Tang, P. C. Loh, P. Wang, F. H. Choo, F. Gao, and F. Blaabjerg, "Generalized design of high performance shunt active power filter with output LCL filter," IEEE Trans. Ind. Electron., Vol. 59, No. 3, pp. 1443-1452, Mar. 2012.

[6] S. Zhang, K. Dai, B. Xie, and Y. Kang, "Parallel control of shunt active power filters in capacity proportion frequency allocation mode," Journal of Power Electronics, Vol. 10, No. 4, pp. 419-427, Jul. 2010.

[7] H. H. Tumbelaka, L. J. Borle, C. V. Nayar, and S. R. Lee, "A grid current-controlling shunt active power filter," Journal of Power Electronics, Vol. 9, No. 3, pp. 365-376, May 2009.

[8] H. M. Suryawanshi, A. K. Kulwal, M. A. Chaudhari, and V. B. Borghate, "High power factor operation of a three-phase rectifier for an adjustable-speed drive," IEEE Trans. Ind. Electron., Vol. 55, No.4, pp. 1637-1646, Apr. 2008.
[9] S. Jiang, D. Cao, Y. Li, J. Liu, and F. Z. Peng, "Low-THD, fast-transient, and cost-effective synchronous-frame repetitive controller for three-phase UPS inverters," IEEE Trans. Power Electron., Vol. 27, No. 6, pp. 2994-3005, Jun. 2012.

[10] K. Mainali, R. Oruganti, K. Viswanathan, and A. P. Ng, "A metric for evaluating the EMI spectra of power converters," IEEE Trans. Power Electron., Vol. 23, No. 4, pp. 2075-2081, Jul. 2008.

[11] G. Shen, D. Xu, L. Cao, and X. Zhu, “An improved control strategy for grid-connected voltage source inverters with an LCL filter," IEEE Trans. Power Electron., Vol. 23, No. 4, pp. 1899-1906, Jul. 2008.

[12] I. J. Gabe, V. F. Montagner, and H. Pinheiro, "Design and implementation of a robust current controller for VSI connected to the grid through an LCL filter," IEEE Trans. Power Electron., Vol. 24, No. 6, pp. 1444-1452, Jun. 2009.

[13] G. Hu, C. Chen, and S. Duan, "New active damping strategy for LCL-filter-based grid-connected inverters with harmonics compensation," Journal of Power Electronics, Vol. 13, No. 2, pp. 287-295, Mar. 2013.

[14] J. Xu, S. Xie, and T. Tang, "Systematic current control strategy with pole assignment for grid-connected LCL-filtered inverters," Journal of Power Electronics, Vol. 13, No. 3, pp. 447-457, May 2013.

[15] L. Zhou, M. Yang, Q. Liu, and K. Guo, "New control strategy for three-phase grid-connected LCL inverters without a phase-locked loop," Journal of Power Electronics, Vol. 13, No. 3, pp. 487-486, May 2013.

[16] Y. Tang, P. C. Loh, P. Wang, F. H. Choo, and F. Gao, "Exploring inherent damping characteristic of LCL-filters for three-phase grid-connected voltage source inverters," IEEE Trans. Power Electron., Vol. 27, No. 3, pp. 1433-1443, Mar. 2012.

[17] D. Ricchiuto, M. Liserre, T. Kerekes, R. Teodorescu, and F. Blaabjerg, "Robustness analysis of active damping methods for an inverter connected to the grid with an LCL-filter," in Proc. IEEE ECCE, pp. 2028-2035, 2011.

[18] T. CY Wang, Z. Ye, G. Sinha, and X. Yuan, "Output filter design for a grid-interconnected three-phase inverter," in Proc. IEEE PESC, pp. 779-784, 2003.

[19] M. Liserre, F. Blaabjerg, and S. Hansen, "Design and control of an LCL-filter-based three-phase active rectifier," IEEE Trans. Ind. Appl., Vol. 41, No. 5, pp. 1281-1291, Sep./Oct. 2005.

[20] R. Pena-Alzola, M. Liserre, F. Blaabjerg, R. Sebastian, J. Dannehl, and F. W. Fuchs, "Analysis of the passive damping losses in LCL-filter-based grid converters," IEEE Trans. Power Electron., Vol. 28, No. 6, pp. 2642-2646, Jun. 2013.

[21] J. Dannehl, M. Liserre, and F. W. Fuchs, "Filter-based active damping of voltage source converters with LCL filter," IEEE Trans. Ind. Electron., Vol. 58, No. 8, pp. 3623-3633, Aug. 2011.

[22] Y. Lei, Z. Zhao, F. He, S. Lu, and L. Yin, "An improved virtual resistance damping method for grid-connected inverters with LCL filters," in Proc. IEEE ECCE, pp. 3816-3822, 2011

[23] E. Wu and P. W. Lehn, "Digital current control of a voltage source with active damping of LCL resonance," IEEE Trans. Power Electron., Vol. 21, No. 5, pp. 1364-1373, Sep. 2006.

[24] M. Malinowski and S. Bernet, "A simple voltage sensorless active damping scheme for three-phase PWM converters with an LCL filter," IEEE Trans. Ind. Electron., Vol. 55, No. 4, pp. 1876-1880, Apr. 2008. 
[25] M. Liserre, A. Dell'Aquila, and F. Blaabjerg, "Genetic algorithm-based design of the active damping for an LCL-filter three-phase active rectifier," IEEE Trans. Power Electron., Vol. 19, No. 1, pp. 76-86, Jan. 2004.

[26] J. Dannehl, F. W. Fuchs, S. Hansen, and P. B. Thøgersen, "Investigation of active damping approaches for PI-based current control of grid-connected pulse width modulation converters with LCL filters," IEEE Trans. Ind. Applicat., Vol. 46, No. 4, pp. 1509-1517, Jul./Aug. 2010.

[27] C. Ö. Gerçek, M. Ermis, A. Ertas, K. N. Köse, and Ö. Ünsar, "Design, implementation, and operation of a new C-type 2nd harmonic filter for electric arc and ladle furnaces," IEEE Trans. Ind. Applicat., Vol. 47, No. 4, pp. 1545-1557, Jul./Aug. 2011.

[28] M.A. Zamani, M. Moghaddasian, M. Joorabian, S.Gh. Seifossadat, and A. Yazdani, "C-type filter design based on power-factor correction for 12-pulse HVDC converters", in Proc. IECON, pp. 3039-3044, 2008.

[29] S. H. E. A. Aleem, A. F. Zobaa, and M. M. A. Aziz, "Optimal C-type passive filter based on minimization of the voltage harmonic distortion for nonlinear loads," IEEE Trans. Ind. Electron., Vol. 59, No. 1, pp. 281-289, Jan. 2012.

[30] Q. Tao, K. Liu, L. Zhou, and Q. Chen, "The Suppression of resonance by a new hybrid power filter," in Proc. ICIEA, 2006.

[31] Q. Chen, Z. Chen, and M. McCormick, "The application and optimization of C-type filter in a combined harmonic power filter," in Proc. IEEE PESC, pp. 1041-1045, 2004.

[32] Q. Tao, K. Liu, X. Zha, and Q. Chen, "The topology and control of a new hybrid power filter," in Proc. IEEE PESC, 2006.

[33] N. Bett, J. N. Nderu, and P. K. Hinga, "Neuro-fuzzy control technique in hybrid power filter for power quality improvement in a three-phase three-wire power system," Innovative Systems Design and Engineering, Vol. 3, No. 4, pp. 41-50, 2012.

[34] K. Borisov, H. L. Ginn III, and G. Chen, "A computationally efficient RDFT-based reference signal generator for active compensators," IEEE Trans. Power Del., Vol. 24, No. 4, pp. 2396-2404, Oct. 2009.

[35] X. Wei, K. Dai, X. Fang, P. Geng, and Y. Kang, "Performance analysis and improvement of output current controller for three-phase shunt active power filter," in Proc. IECON, pp. 1757-1761, 2006.

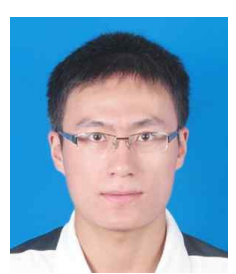

Cong Liu was born in Hunan, China, in 1986. He received his B.E. in Electronic Information Engineering from Zhejiang University, Hangzhou, China, in 2008. Since 2008, he has been with the School of Electrical and Electronic Engineering, Huazhong University of Science and Technology, Wuhan, China, where he is currently working toward his Ph.D. in Electrical Engineering. His current research interests include power quality conditioning, power distribution system harmonic analysis and suppression, and power electronic converters.

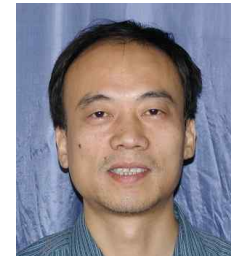

Ke Dai was born in Hunan, China, in 1969. He received his M.E. from Wuhan University of Technology, Wuhan, China, in 1998, and his B.E. and Ph.D. from Huazhong University of Science and Technology (HUST), Wuhan, China, in 1990 and 2003, respectively. From 1990 to 1995 , he was an Assistant Electric Engineer in the Institute of Wuhan Marine Electric Power Propulsion, Wuhan, China. He is currently an Associate Professor in the Division of Applied Electronic Engineering, School of Electrical and Electronic Engineering, HUST. He is the author or coauthor of more than 50 papers and is the holder of 2 issued patents. His current research interests include the application of power electronics for power quality, power reliability, and utility and industrial applications. Dr. Dai was the recipient of the 2010 Innovation Award from Hubei Science and Technology Bureau for his contributions in active power filters and static VAR compensators. He is a senior member of the Chinese Electrician Society and the Chinese Power Supply Society.

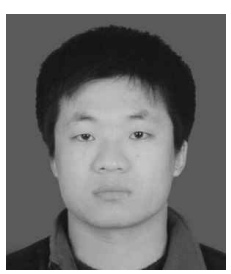

Kewei Duan was born in Hubei, China, in 1986. He received his B.E. in Electrical Engineering from China University of Petroleum, Shandong, China, and his M.E. in Electrical Engineering from Huazhong University of Science and Technology, Wuhan, China, in 2009 and 2013, respectively. He is currently working at the Electric Power Training Center, State Grid Hunan Electric Power Company, Changsha, China. His current research interests include power quality and power electronic converters.

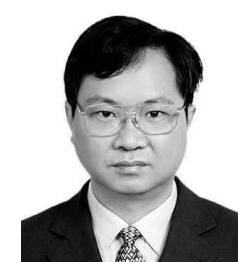

Yong Kang was born in Hubei, China, in 1965. He received his B.E., M.E., and Ph.D. from Huazhong University of Science and Technology (HUST), Wuhan, China, in 1988 1991 and 1994, respectively. In 1994, he joined HUST as a Lecturer and was promoted to an Associate Professor in 1996 and to Full Professor in 1998. He is currently the Head of the School of Electrical and Electronic Engineering, HUST. His current research interests include power electronic converters, ac drivers, electromagnetic compatibility, and digital control techniques. He has authored or coauthored more than 60 technical papers. 